\title{
Psychological Distress among Individuals Whose Partners Have Cancer
}

\author{
Naoki Nakaya, ${ }^{1}$ Toshimasa Sone, ${ }^{2}$ Kumi Nakaya, ${ }^{1}$ Yasutake Tomata, ${ }^{3}$ \\ Atsushi Hozawa ${ }^{1}$ and Ichiro Tsuji ${ }^{3}$
}

\author{
${ }^{1}$ Department of Preventive Medicine and Epidemiology, Tohoku Medical Megabank Organization, Tohoku \\ University, Sendai, Miyagi, Japan \\ ${ }^{2}$ Department of Rehabilitation, Faculty of Health Science, Tohoku Fukushi University, Sendai, Miyagi, Japan \\ ${ }^{3}$ Division of Epidemiology, Department of Health Informatics and Public Health, Tohoku University Graduate \\ School of Medicine, Sendai, Miyagi, Japan
}

\begin{abstract}
Cancer diagnosis influences both patients and their closest relatives. This cross-sectional study examined psychological distress among individuals whose partners had cancer in a population-based sample. Participants in the survey were citizens residing in Ohsaki City, Miyagi, Japan. Spouse pairs were identified by information of participants' relationship to the householder and address provided by municipality, and we collected self-report information on cancer history and current pain (but not the cause of pain). Psychological distress was evaluated using the Kessler 6 scale (K6). We identified 29,410 potential participants $(14,705$ couples), of which 23,766 (11,690 men and 12,076 women) were included in the analyses. A total of 1,374 participants (581 male and 793 female participants) had partners with history of cancer. Logistic regression analyses revealed that these participants, regardless of sex, did not show significantly higher risk of psychological distress (K6 score $\geq 13$ ). When stratifying the analysis by partners' current pain, men whose partners had cancer and pain showed greater odds of psychological distress (odds ratio $=1.5, p=0.04$ ), compared with men whose partners had no cancer and had pain. However, male subjects whose partners had cancer but no pain did not show greater odds of psychological distress compared with men whose partners had no cancer and no pain. By contrast, in women whose partners had cancer, psychological distress was not associated with pain status. In conclusion, men whose partners had cancer and pain have higher risk of psychological distress, and its screening to these individuals may reduce the risk.
\end{abstract}

Keywords: cancer history, cross-sectional study, current pain, partners, psychological distress Tohoku J. Exp. Med., 2017 September, 243 (1), 27-33. (C) 2017 Tohoku University Medical Press

\section{Introduction}

Individuals with a history of chronic disease, including cancer, might experience significant psychological distress (Nakaya et al. 2014). Furthermore, chronic diseases do not appear to only affect patients, but also their closest relatives (House et al. 1988). For instance, caregivers, including partners or other family members, of patients with chronic diseases appear to show high levels of fatigue (Fletcher et al. 2008). The mechanism of this effect might involve several interacting pathways: the event might cause stress in the partner; it might deprive the partner of necessary emotional, social, and economic support; and it might influence the daily life and behavior of the partner (House et al. 1988; Kawachi and Berkman 2001).

A large cohort study in the USA examined the association between the hospitalization of a spouse and mortality among 518,240 elderly couples (Christakis and Allison 2006). They found that spouse's hospitalization greatly contributed to the risk of mortality in both men and women, making it clear that the hospitalization of a spouse has serious adverse health effects. Furthermore, there have been many epidemiological studies on the mental problems of partners of cancer patients (Kornblith et al. 1994; Toseland et al. 1995; Nijboer et al. 2001; Baider et al. 2003; Bishop et al. 2007; Rhee et al. 2008; Sjövall et al. 2009; Nakaya et al. 2010, 2016b; Moser et al. 2013; Oba et al. 2014). Nakaya et al. (2010) reported that men whose partners were diagnosed with breast cancer had an increased risk of being hospitalized with an affective disorder, and the risk showed a dose-response relationship with the severity of breast cancer. A previous study indicated that presence of pain in cancer patients adversely affects the psychological mood disturbance of family caregivers. Therefore, psychological

Received June 7, 2017; revised and accepted August 24, 2017. Published online September 13, 2017; doi: 10.1620/tjem.243.27.

Correspondence: Naoki Nakaya, Ph.D., Department of Preventive Medicine and Epidemiology, Tohoku Medical Megabank Organization,

Tohoku University, 2-1 Seiryo-machi, Aoba-ku, Sendai, Miyagi 980-8573, Japan.

e-mail: nakaya-thk@umin.ac.jp 
distress among individuals whose partners have cancer might increase (Miaskowski et al. 1997). In Japan, there have been a few reports indicating that the partners of patients with cancer have an increased risk of psychological distress compared with control groups. Problematically, however, these studies relied on small sample sizes (number of partners of cancer patients $=72$ (Nakaya et al. 2016b) to 99 (Oba et al. 2014)).

To address this issue of small sample sizes, the present cross-sectional study in Japan used a population-based sample to examine the psychological distress of individuals whose partners had cancer. We conceived two hypotheses, as follows: (1) Psychological distress will be higher among individuals whose partners had cancer, and (2) Psychological distress will be even higher among individuals whose partners had cancer and pain.

\section{Methods}

\section{Study design, setting, and participants}

The design of the Ohsaki Cohort 2006 Study has been described in detail elsewhere (Kuriyama et al. 2009, 2010). Briefly, the population of the baseline survey comprised all males and females who were 40 years or older living in Ohsaki City, northeastern Japan, on December 1, 2006 (a total population of 77,235). The baseline survey was conducted between December 1 and 15, 2006. A questionnaire was distributed by the heads of individual administrative districts to individual households and then collected by mail. Of the 77,235 eligible respondents, 49,855 who provided valid responses formed the study cohort. Spouse pairs were identified by information of relationships in household and address provided by the public records of Ohsaki City. We defined partners as follows, using the information on participants' relationship to the householder: head of householdwife, head of household-husband, mother of head of household-father of head of household, and mother of spouse-father of spouse. Through this matching process, we identified 29,410 potential participants (14,705 pairs). We then excluded 3,472 participants with missing answers on the Kessler 6 scale (K6), and 2,172 participants who had self-reported a history of stroke $(n=628)$ or cancer $(n=1,544)$. This latter exclusion was because participants with these diseases were expected to have high psychological distress (K6) scores, independently of their partners' cancer. Finally, data for 23,766 participants $($ men $=11,690$, women $=12,076)$ were included in the following analyses.

\section{Measurements}

The questionnaire, which targeted persons aged 40 years old or older, requested the following information from each participant: past history of chronic disease (self-reported diabetes mellitus, hyperlipidemia, hypertension, myocardial infarction, gastric or duodenal ulcer, liver disease, or kidney disease), lifestyle habits (smoking status, alcohol drinking status, time spent walking), social factors (educational background and social support), self-reported current pain at baseline survey, and psychological distress (using the K6; see below).

Self-reported current pain at baseline was assessed with the following question: "How much pain have you had during the past 4 weeks?" Six response options were provided: none, slight, mild, moderate, severe, and very severe. We grouped participants by their answers into two groups: no pain or have pain (slight to very severe).
Unfortunately, the Ohsaki Cohort 2006 Study obtained no data on the cause of the pain.

The $\mathrm{K} 6$ was used to assess psychological distress in this study. This scale is typically used as a screening tool for anxiety and mood disorders (Kessler et al. 2002, 2003). The Japanese version of the K6 was developed by using the standard back-translation method, and has been validated (Furukawa et al. 2008). The K6 comprises six questions assessing how often an individual has felt the following in the last month: (1) nervous, (2) hopeless, (3) restless or fidgety, (4) so sad that nothing could cheer you up, (5) everything is an effort, or (6) worthless. The possible responses and their scores were as follows: "all of the time" (4 points), "most of the time" (3 points), "some of the time" ( 2 points), "little of the time" ( 1 point), and "none of the time" (0 points). The total K6 score for the six questions ranges from 0 to 24 , and higher scores tend to have psychological distress. In a previous study, a cut-off of $\geq 13$ was used to screen for psychological distress (Kuriyama et al. 2010; Nakaya et al. 2016a; Forman-Hoffman et al. 2017). Thus, we classified respondents with scores of $\geq 13$ out of 24 as having a higher degree of psychological distress.

\section{Ethical issues}

We considered the return of completed questionnaires as consent to participate in the study, for both the baseline survey data. The Ethics Committee of Tohoku University Graduate School of Medicine (Sendai, Japan) reviewed and approved the study protocol.

\section{Statistical analysis}

First, we used Chi-square tests to examine the differences in demographic, lifestyle, and socioeconomic characteristics according to partners' history of cancer, stratified by sex. Second, logistic regression analysis was used to calculate the odds ratios (ORs) and 95\% confidence intervals (CIs) for psychological distress (K6 score $\geq$ 13) among participants according to their partners' history of cancer; this analysis was also stratified by sex.

Third, we performed another set of logistic regression analyses, and this analysis was stratified by partners' current pain. In this analysis, we tested the hypothesis of whether participants whose partners had cancer and pain had an even higher risk of psychological distress than did those whose partners had cancer but no pain.

Finally, we divided participants into four groups according to their partners' history of cancer (did not have cancer or had cancer) and current pain (did not have pain or had pain), as follows: had no cancer and no pain; had no cancer and had pain; had cancer and had no pain; and had cancer and pain. This enabled us to fit a logistic regression model testing the interaction between partners' cancer and current pain on psychological distress, stratified by sex. The interaction analysis excluded participants whose partners did not respond to the question on current pain at baseline $(n=761)$.

In all of the above logistic regressions, we included the following variables as potential confounders: age at baseline in years $(\leq 64$, $65-74$, or $\geq 75)$, last age of educational background in years $(\leq 15$, $16-18, \geq 19$, or unknown), smoking status (never smokers, former smokers, current smokers, or unknown), alcohol drinking status (never drinkers, former drinkers, current drinkers, or unknown), time spent walking ( $\leq 0.5 \mathrm{~h} /$ day, $0.5-1 \mathrm{~h} /$ day, $\geq 1 \mathrm{~h} /$ day, or unknown), social support (i.e., others to consult when in trouble; sufficient, lacking, unknown), and self-reported history of chronic disease (absence, presence). For this last variable, the diseases considered were diabetes mellitus, hyperlipidemia, hypertension, myocardial infarction, 
gastric or duodenal ulcer, liver disease, or kidney disease.

All statistical analyses were performed using SAS version 9.4 (SAS Inc., Cary, NC, USA). Differences at $\mathrm{p}<0.05$ were considered statistically significant.

\section{Results}

Table 1 summarizes the demographic, lifestyle, and socioeconomic characteristics of participants according to their partners' history of cancer, stratified by sex. A total of 1,374 participants (581 male and 793 female participants) had partners with history of cancer.

Participants (regardless of sex) whose partners had cancer tended to be older, not current drinkers, and with a history of chronic disease. Among men only, those whose partners had cancer tended to spend less time walking. By contrast, among women only, those whose partners had cancer tended to have a lower educational level. The prevalence of psychological distress (K6 score $\geq 13$ ) was $4 \%$ among men and $6 \%$ among women, respectively.

Table 2 shows the multivariate adjusted ORs and 95\% CIs for psychological distress (K6 score $\geq 13$ ) according to partners' history of cancer, stratified by sex. Participants, regardless of sex, whose partners had cancer did not show significantly higher odds of psychological distress.

Table 1. Demographic, lifestyle, and socioeconomic characteristics of participants according to the history of cancer of their partners stratified by sex (Ohsaki Cohort 2006 Study).

\begin{tabular}{|c|c|c|c|c|c|c|}
\hline & $\begin{array}{l}\text { Male participants } \\
\text { whose partners } \\
\text { had no cancer } \\
(n=11,109)\end{array}$ & $\begin{array}{l}\text { Male participants } \\
\text { whose partners } \\
\text { had cancer } \\
(n=581)\end{array}$ & $\begin{array}{c}\text { p-value } \\
\text { (Chi-squa } \\
\text { re test) }\end{array}$ & $\begin{array}{l}\text { Female participants } \\
\text { whose partners } \\
\text { had no cancer } \\
(n=11,283)\end{array}$ & $\begin{array}{l}\text { Female participants } \\
\text { whose partners } \\
\text { had cancer } \\
\underline{(n=793)}\end{array}$ & $\begin{array}{c}\text { p-value } \\
\text { (Chi-squa } \\
\text { re test) }\end{array}$ \\
\hline \multicolumn{7}{|c|}{ Age at baseline, years $(\%)$} \\
\hline$\leq 64$ & $6,098(55)$ & $251(43)$ & \multirow{3}{*}{$<0.01$} & $7,179(64)$ & $276(35)$ & \multirow{3}{*}{$<0.01$} \\
\hline $65-74$ & $3,138(28)$ & $205(35)$ & & $2,920(26)$ & $360(45)$ & \\
\hline$\geq 75$ & $1,873(17)$ & $125(22)$ & & $1,184(10)$ & $157(20)$ & \\
\hline \multicolumn{7}{|c|}{ Last age of educational background, years (\%) } \\
\hline$\leq 15$ & $2,384(21)$ & $139(24)$ & \multirow{4}{*}{0.39} & $1,529(14)$ & $143(18)$ & \multirow{4}{*}{$<0.01$} \\
\hline $16-18$ & $5,671(51)$ & $290(50)$ & & $5,608(50)$ & $353(45)$ & \\
\hline$\geq 19$ & $2,669(24)$ & $137(24)$ & & $3,717(33)$ & $257(32)$ & \\
\hline Unknown & $385(3)$ & $15(3)$ & & $429(4)$ & $40(5)$ & \\
\hline \multicolumn{7}{|c|}{ Smoking status (\%) } \\
\hline Never & $2,251(20)$ & $130(22)$ & \multirow{4}{*}{0.25} & $8,888(79)$ & $646(81)$ & \multirow{4}{*}{$<0.01$} \\
\hline Former & $4,582(41)$ & $250(43)$ & & $472(4)$ & $22(3)$ & \\
\hline Current & $4,026(36)$ & $191(33)$ & & $736(7)$ & $27(3)$ & \\
\hline Unknown & $250(2)$ & $10(2)$ & & $1,187(11)$ & $98(12)$ & \\
\hline \multicolumn{7}{|c|}{ Alcohol drinking status (\%) } \\
\hline Never & $1,175(20)$ & $94(16)$ & \multirow{4}{*}{0.03} & $6,597(58)$ & $534(67)$ & \multirow{2}{*}{$<0.01$} \\
\hline Former & $1,162(10)$ & $82(14)$ & & $511(5)$ & $26(3)$ & \\
\hline Current & $7,997(72)$ & $394(68)$ & & $3,247(29)$ & $146(18)$ & \\
\hline Unknown & $175(2)$ & $11(2)$ & & $928(8)$ & $87(11)$ & \\
\hline \multicolumn{7}{|c|}{ Time spent walking (\%) } \\
\hline$\leq 0.5 \mathrm{~h} /$ day & $3,729(34)$ & $186(32)$ & \multirow{4}{*}{0.01} & $4,115(36)$ & $287(36)$ & \multirow{4}{*}{0.41} \\
\hline $0.5-1 \mathrm{~h} / \mathrm{day}$ & $3,675(33)$ & $229(39)$ & & $3,794(34)$ & $274(35)$ & \\
\hline$\geq 1$ h/day & $3,486(31)$ & $157(27)$ & & $3,111(28)$ & $207(26)$ & \\
\hline Unknown & $219(2)$ & $9(2)$ & & $263(2)$ & $25(3)$ & \\
\hline \multicolumn{7}{|c|}{ Social support: others to consult when in trouble (\%) } \\
\hline Sufficient & $9,465(85)$ & $497(86)$ & \multirow{3}{*}{0.22} & $10,347(86)$ & $743(94)$ & \multirow{3}{*}{0.13} \\
\hline Lacking & $1,588(14)$ & $84(14)$ & & $892(8)$ & $48(6)$ & \\
\hline Unknown & $56(1)$ & $0(0)$ & & $44(0)$ & $2(0)$ & \\
\hline \multicolumn{7}{|c|}{ Self-reported history of chronic disease (\%) } \\
\hline Absence & $5,851(53)$ & $276(48)$ & \multirow{2}{*}{0.02} & $6,778(60)$ & $408(51)$ & \multirow{2}{*}{$<0.01$} \\
\hline Presence & $5,258(47)$ & $305(53)$ & & $4,505(40)$ & $385(49)$ & \\
\hline \multicolumn{7}{|c|}{ Partners' pain status (\%) } \\
\hline No pain & $2,549(23)$ & $122(21)$ & \multirow{3}{*}{0.53} & $3,309(30)$ & $228(29)$ & \multirow{3}{*}{0.36} \\
\hline Have pain & $8,202(74)$ & $441(76)$ & & $7,528(67)$ & $545(69)$ & \\
\hline Unknown & $358(3)$ & $18(3)$ & & $365(3)$ & $20(3)$ & \\
\hline
\end{tabular}


Table 2. Odds ratios (ORs) and 95\% confidence intervals (CI) for psychological distress (K6 score $\geq 13$ ) of participants according to their partners' history of cancer, stratified by sex (Ohsaki Cohort 2006 Study).

\begin{tabular}{|l|c|c|c|c|}
\hline & $\begin{array}{c}\text { Male participants } \\
\text { whose partners } \\
\text { had no cancer }\end{array}$ & $\begin{array}{c}\text { Male participants } \\
\text { whose partners } \\
\text { had cancer }\end{array}$ & $\begin{array}{c}\text { Female participants } \\
\text { whose partners } \\
\text { had no cancer }\end{array}$ & $\begin{array}{c}\text { Female participants } \\
\text { whose partners } \\
\text { had cancer }\end{array}$ \\
\hline $\begin{array}{l}\text { No. of subjects, } \\
\begin{array}{l}\text { No. of subjects with K6 score } \geq 13 \\
(\%)\end{array}\end{array} \quad \begin{array}{c}581 \\
11,109\end{array}$ & $30(5)$ & $684(6)$ & 793 \\
\hline $\begin{array}{l}\text { Multivariate adjusted OR (95\% } \\
\text { Cl)* } \\
\text { p-value }\end{array}$ & 1.0 (ref) & $1.2(0.8-1.7)$ & 1.0 (ref) & $1.0(0.7-1.3)$ \\
\end{tabular}

*Adjusted for age at baseline in years, last age of educational background in years, smoking status, alcohol drinking status, time spent walking, social support, self-reported history of chronic disease.

Table 3. Odds ratios (OR) and 95\% confidence intervals (CI) for psychological distress (K6 score $\geq 13)$ of participants according to their partner's history of cancer, stratified by partners' pain status and sex (Ohsaki Cohort 2006 Study)*.

\begin{tabular}{|c|c|c|c|c|}
\hline & $\begin{array}{l}\text { Male participants } \\
\text { whose partners } \\
\text { had no cancer }\end{array}$ & $\begin{array}{c}\text { Male participants } \\
\text { whose partners } \\
\text { had cancer }\end{array}$ & $\begin{array}{c}\text { Female participants } \\
\text { whose partners } \\
\text { had no cancer }\end{array}$ & $\begin{array}{c}\text { Female participants } \\
\text { whose partners } \\
\text { had cancer }\end{array}$ \\
\hline \multicolumn{5}{|c|}{ Participants whose partners had no pain $(n=6,289)$} \\
\hline $\begin{array}{l}\text { No. of subjects, } \\
\text { No. of subjects with } K 6 \text { score } \geq 13 \\
(\%)\end{array}$ & $\begin{array}{l}2,549 \\
94(4)\end{array}$ & $\begin{array}{l}122 \\
1(1)\end{array}$ & $\begin{array}{c}3,390 \\
160(5)\end{array}$ & $\begin{array}{c}228 \\
15(7)\end{array}$ \\
\hline $\begin{array}{l}\text { Multivariate adjusted OR }(95 \% \\
\mathrm{Cl}) \dagger \\
\text { p-value }\end{array}$ & 1.0 (ref) & $\begin{array}{c}0.2(0.01-1.05) \\
0.12\end{array}$ & $\begin{array}{c}1.0 \text { (ref) } \\
-\end{array}$ & $1.4(0.8-2.4)$ \\
\hline \multicolumn{5}{|c|}{ Participants whose partners had pain (slight to very severe; $n=16,716$ ) } \\
\hline $\begin{array}{l}\text { No. of subjects, } \\
\text { No. of subjects with } K 6 \text { score } \geq 13 \\
\text { (\%) }\end{array}$ & $\begin{array}{c}8,202 \\
380(5)\end{array}$ & $\begin{array}{c}441 \\
29(7)\end{array}$ & $\begin{array}{c}7,528 \\
551(7)\end{array}$ & $\begin{array}{c}545 \\
31(6)\end{array}$ \\
\hline $\begin{array}{l}\text { Multivariate adjusted OR }(95 \% \\
\mathrm{CI})^{\dagger} \\
\mathrm{p} \text {-value }\end{array}$ & 1.0 (ref) & $\begin{array}{l}1.5(1.01-2.2) \\
0.04\end{array}$ & 1.0 (ref) & $0.9(0.6-1.2)$ \\
\hline
\end{tabular}

*Data for participants whose partners did not respond to the question on pain $(n=761)$ were deleted.

${ }^{\dagger}$ Adjusted for age at baseline in years, last age of educational background in years, smoking status, alcohol drinking status, time spent walking, social support, self-reported history of chronic disease.

Table 3 shows the multivariate adjusted ORs for participants according to the history of partners' cancer, stratified by partners' current pain and sex. Men whose partners had cancer and pain had higher odds of psychological distress $(\mathrm{OR}=1.5,95 \%$ confidence interval $[\mathrm{CI}]=1.01-2.2, \mathrm{p}$ $=0.04)$ compared with those whose partners had no cancer but did have pain. On the other hand, men whose partners had cancer and no pain did not show a higher odds of psychological distress $(\mathrm{OR}=0.2,95 \% \mathrm{CI}=0.01-1.05, \mathrm{p}=$ 0.12 ) compared to those whose partners had no cancer but did have pain. Women whose partners had cancer both with $(\mathrm{OR}=0.9,95 \% \mathrm{CI}=0.6-1.2, \mathrm{p}=0.45)$ and without $(\mathrm{OR}=$ $1.4,95 \% \mathrm{CI}=0.8-2.4, \mathrm{p}=0.24)$ pain did not show higher odds of psychological distress (Table 3 ).

Finally, Table 4 shows the association of psychological distress (K6 score $\geq 13$ ) according to the interaction of partners' cancer and pain status, stratified by sex. Men whose partners had cancer and pain showed significantly higher odds of psychological distress $(\mathrm{OR}=1.8,95 \% \mathrm{CI}=1.1-2.7$, $\mathrm{p}=0.01$ ) compared to men whose partners had no cancer and no pain. On the other hand, women whose partners had cancer and pain did not show significantly higher odds of psychological distress $(\mathrm{OR}=1.2,95 \% \mathrm{CI}=0.8-1.8, \mathrm{p}=$ $0.29)$ compared to those whose partners had no cancer and no pain.

Overall, we found that the estimated effect of partners' history of cancer on psychological distress was significantly modified by pain status in men $(\mathrm{p}=0.03)$ but not in women $(\mathrm{p}=0.75)$.

\section{Discussion}

This cross-sectional study in Japan examined the levels of psychological distress among individuals whose partners had cancer, using a population-based sample. We 
Table 4. Odds ratios (OR) and 95\% confidence intervals (CI) for psychological distress (K6 score $\geq 13$ ) of participants according to combinations of partners' cancer and pain status, stratified by sex (Ohsaki Cohort 2006 Study)*.

\begin{tabular}{|c|c|c|c|c|}
\hline & $\begin{array}{c}\text { Participants whose } \\
\text { partners had no cancer } \\
\text { AND } \\
\text { had no pain }\end{array}$ & $\begin{array}{c}\text { Participants whose } \\
\text { partners had no cancer } \\
\text { AND } \\
\text { had pain }\end{array}$ & $\begin{array}{l}\text { Participants whose } \\
\text { partners had cancer } \\
\text { AND } \\
\text { had no pain }\end{array}$ & $\begin{array}{c}\text { Participants whose } \\
\text { partners had cancer } \\
\text { AND } \\
\underline{\underline{\text { had pain }}}\end{array}$ \\
\hline \multicolumn{5}{|c|}{ Male participants according to combination of partners' cancer and pain status $(n=11,314)$} \\
\hline $\begin{array}{l}\text { No. of male subjects, } \\
\text { No. of male subjects with } \mathrm{K} 6 \\
\text { score } \geq 13(\%)\end{array}$ & $\begin{array}{l}2,549 \\
94(4)\end{array}$ & $\begin{array}{c}122 \\
1(1)\end{array}$ & $\begin{array}{c}8,202 \\
380(5)\end{array}$ & $\begin{array}{c}441 \\
29(6)\end{array}$ \\
\hline $\begin{array}{l}\text { Multivariate adjusted OR }(95 \% \\
\mathrm{CI})^{\dagger} \\
\text { p-value }\end{array}$ & $\begin{array}{c}1.0 \text { (ref) } \\
-\end{array}$ & $\begin{array}{c}0.2(0.01-1.05) \\
0.12\end{array}$ & $\begin{array}{c}1.2(0.6-1.5) \\
0.13\end{array}$ & $\begin{array}{c}1.8(1.1-2.7) \\
0.01\end{array}$ \\
\hline \multicolumn{5}{|c|}{ Female participants according to combination of partners' cancer and pain status ( $n=11,691)$} \\
\hline $\begin{array}{l}\text { No. of female subjects, } \\
\text { No. of female subjects with K6 } \\
\text { score } \geq 13(\%)\end{array}$ & $\begin{array}{c}3,390 \\
160(5)\end{array}$ & $\begin{array}{c}228 \\
15(7)\end{array}$ & $\begin{array}{c}7,528 \\
511(7)\end{array}$ & $\begin{array}{c}545 \\
31(6)\end{array}$ \\
\hline $\begin{array}{l}\text { Multivariate adjusted OR }(95 \% \\
\mathrm{CI})^{\dagger} \\
\text { p-value }\end{array}$ & 1.0 (ref) & $\begin{array}{c}1.5(0.8-2.5) \\
0.18\end{array}$ & $\begin{array}{c}1.5(1.2-1.8) \\
<0.01\end{array}$ & $\begin{array}{c}1.2(0.8-1.8) \\
0.29\end{array}$ \\
\hline
\end{tabular}

*Data for participants whose partners did not respond to the question on pain $(n=761)$ were deleted.

${ }^{\dagger}$ Adjusted for age at baseline in years, last age of educational background in years, smoking status, alcohol drinking status, time spent walking, social support, self-reported history of chronic disease.

hypothesized that psychological distress would be higher in individuals whose partners had cancer, and that having current pain would be associated with even higher psychological distress. The first hypothesis was not supported, but the second hypothesis seemed to be partially supported (it was found only among men). Participants, regardless of sex, whose partners had cancer did not show a significantly higher risk of psychological distress. However, men whose partners had cancer with pain did have a higher risk of psychological distress, whereas men whose partners had cancer but no pain did not show a higher risk. Earlier studies showed that participants whose partners have cancer were more likely to have negative psychological symptoms such as depression and anxiety (Kornblith et al. 1994; Toseland et al. 1995; Nijboer et al. 2001; Baider et al. 2003; Bishop et al. 2007; Rhee et al. 2008; Sjovall et al. 2009; Nakaya et al. 2010, 2016b; Moser et al. 2013; Oba et al. 2014). Thus, our results differ from those of these earlier studies. We suggest two reasons for this. First, there is selection biasparticipants might have had naturally lower degrees of psychological distress, with persons who had higher degrees of distress having refused to participate. Second, this study focused on the subjects whose partners had a history of cancer, which means that some of the partners with cancer had already completed treatment by the time study recruitment commenced. Although we included partners who needed extensive cancer-related treatments, it is likely that those with a history of cancer who had completed treatment had lower psychological distress overall.

We attempted, however, to limit the possible bias caused by this by performing the stratified analysis by pain status. The stratified analysis by the partners' pain status, as noted above, revealed that men whose partners had cancer with pain had a higher risk of psychological distress, but men whose partners had cancer but no pain did not show a higher risk. Taken together, these results indicate that greater psychological care is necessary for men whose partners had cancer and pain. It might be necessary to screen for psychological distress among the male partners of patients with cancer in general, particularly those experiencing pain; this could help in preventing this potentially devastating consequence of cancer. For instance, medical professionals could confirm partners' history of cancer and clinical cancer status at the time of annual health check-ups, and might screen for psychological distress among individuals whose partners have a history of cancer.

Current pain had no effect on the risk of psychological distress among women. At present, we do not know the precise reason for this. We speculate that women have much more social support from friends and/or neighbors than do men in the Japanese population (Yoshii et al. 2005).

This study had several advantages. First, we identified spousal pairs using participants' relationship to the householder and address by the public records of municipality. Second, our study considered various potential confounding variables, such as demographic characteristics, socioeconomic status, lifestyles, and participants' own history of chronic disease. Therefore, the psychological distress among individuals whose partners had cancer was assessed for each variable independently.

The present study had several limitations. First, while we focused on the psychological distress of participants 
whose partners had cancer, we did not have actual data on partners' clinical cancer status (e.g., cancer sites, cancer stage). Similarly, we could not clarify whether the pain of the partners was caused by the cancer or by another condition. Second, although we had a large, population-based sample of about 11,000 spousal pairs, only a limited number of participants' partners had a history of cancer (a total of 1,374 cases $(5.7 \%)$ ). This might have made the results statistically unstable because there was a small number of events (i.e., individuals with psychological distress) when we conducted the stratified analysis by current pain. Third, because of the cross-sectional design, we could not draw any conclusions regarding the causal relationships between partners' cancer and the risk of psychological distress. However, a reverse causal relationship between them seems unlikely. Finally, the assessment of psychological distress was performed using the K6, which is not a robust psychological scale. Further study is needed to focus on more severe psychiatric outcomes such as anxiety and mood disorders.

In conclusion, in this cross-sectional study with a population-based sample in Japan, we found that men whose partners had cancer and pain had a higher risk of psychological distress, whereas men whose partners had cancer but did not have current pain did not show a higher risk. These results suggested that a history of cancer not only affects the life of the person with the diagnosis, but also their male partners. These interpersonal effects of cancer diagnosis on mental health care challenge our understanding of cancer as a physical disease, as it seems to have important psychosocial effects. We suggest that a screening system for psychological distress be put in place targeting both people with cancer and their partners, as this could help in preventing this potentially devastating consequence of cancer.

\section{Acknowledgments}

This work was supported by a Grant-in-Aid for Scientific Research (C) (No. 26350863) (No. 17K04190) from the Japanese Society for the Promotion of Science (JSPS), as well as a Grant-in-Aid from the Kurokawa Cancer Research Foundation.

\section{Conflict of Interest}

The authors declare no conflict of interest.

\section{References}

Baider, L., Ever-Hadani, P., Goldzweig, G., Wygoda, M.R. \& Peretz, T. (2003) Is perceived family support a relevant variable in psychological distress? A sample of prostate and breast cancer couples. J. Psychosom. Res., 55, 453-460.

Bishop, M.M., Beaumont, J.L., Hahn, E.A., Cella, D., Andrykowski, M.A., Brady, M.J., Horowitz, M.M., Sobocinski, K.A., Rizzo, J.D. \& Wingard, J.R. (2007) Late effects of cancer and hematopoietic stem-cell transplantation on spouses or partners compared with survivors and survivor-matched controls. J. Clin. Oncol., 25, 1403-1411.

Christakis, N.A. \& Allison, P.D. (2006) Mortality after the hospitalization of a spouse. N. Engl. J. Med., 354, 719-730.
Fletcher, B.S., Paul, S.M., Dodd, M.J., Schumacher, K., West, C., Cooper, B., Lee, K., Aouizerat, B., Swift, P., Wara, W. \& Miaskowski, C.A. (2008) Prevalence, severity, and impact of symptoms on female family caregivers of patients at the initiation of radiation therapy for prostate cancer. J. Clin. Oncol., 26, 599-605.

Forman-Hoffman, V.L., Hedden, S.L., Miller, G.K., Brown, K., Teich, J. \& Gfroerer, J. (2017) Trends in cigarette use, by serious psychological distress status in the United States, 1998-2013. Addict. Behav., 64, 223-228.

Furukawa, T.A., Kawakami, N., Saitoh, M., Ono, Y., Nakane, Y., Nakamura, Y., Tachimori, H., Iwata, N., Uda, H., Nakane, H., Watanabe, M., Naganuma, Y., Hata, Y., Kobayashi, M., Miyake, Y., Takeshima, T. \& Kikkawa, T. (2008) The performance of the Japanese version of the K6 and K10 in the World Mental Health Survey Japan. Int. J. Methods Psychiatr. Res., 17, 152-158.

House, J.S., Landis, K.R. \& Umberson, D. (1988) Social relationships and health. Science, 241, 540-545.

Kawachi, I. \& Berkman, L.F. (2001) Social ties and mental health. J. Urban Health, 78, 458-467.

Kessler, R.C., Andrews, G., Colpe, L.J., Hiripi, E., Mroczek, D.K., Normand, S.L., Walters, E.E. \& Zaslavsky, A.M. (2002) Short screening scales to monitor population prevalences and trends in non-specific psychological distress. Psychol. Med., 32, 959-976.

Kessler, R.C., Barker, P.R., Colpe, L.J., Epstein, J.F., Gfroerer, J.C., Hiripi, E., Howes, M.J., Normand, S.L., Manderscheid, R.W., Walters, E.E. \& Zaslavsky, A.M. (2003) Screening for serious mental illness in the general population. Arch. Gen. Psychiatry, 60, 184-189.

Kornblith, A.B., Herr, H.W., Ofman, U.S., Scher, H.I. \& Holland, J.C. (1994) Quality of life of patients with prostate cancer and their spouses. The value of a data base in clinical care. Cancer, 73, 2791-2802.

Kuriyama, S., Nakaya, N., Ohmori-Matsuda, K., Shimazu, T., Kikuchi, N., Kakizaki, M., Sone, T., Sato, F., Nagai, M., Sugawara, Y., Akhter, M., Higashiguchi, M., Fukuchi, N., Takahashi, H., Hozawa, A. \& Tsuji, I. (2009) Factors associated with psychological distress in a community-dwelling Japanese population: the Ohsaki Cohort 2006 Study. J. Epidemiol., 19, 294-302.

Kuriyama, S., Nakaya, N., Ohmori-Matsuda, K., Shimazu, T., Kikuchi, N., Kakizaki, M., Sone, T., Sato, F., Nagai, M., Sugawara, Y., Tomata, Y., Akhter, M., Higashiguchi, M., Fukuchi, N., Takahashi, H., Hozawa, A. \& Tsuji, I. (2010) The Ohsaki Cohort 2006 Study: design of study and profile of participants at baseline. J. Epidemiol., 20, 253-258.

Miaskowski, C., Kragness, L., Dibble, S. \& Wallhagen, M. (1997) Differences in mood states, health status, and caregiver strain between family caregivers of oncology outpatients with and without cancer-related pain. J. Pain Symptom Manage., 13, 138-147.

Moser, M.T., Künzler, A., Nussbeck, F., Bargetzi, M. \& Znoj, H.J. (2013) Higher emotional distress in female partners of cancer patients: prevalence and patient-partner interdependencies in a 3-year cohort. Psychooncology, 22, 2693-2701.

Nakaya, N., Saito-Nakaya, K., Bidstrup, P.E., Dalton, S.O., Frederiksen, K., Steding-Jessen, M., Uchitomi. Y. \& Johansen, C. (2010) Increased risk of severe depression in male partners of women with breast cancer. Cancer, 116, 5527-5534.

Nakaya, N., Kogure, M., Saito-Nakaya, K., Tomata, Y., Sone, T., Kakizaki, M. \& Tsuji, I. (2014) The association between selfreported history of physical diseases and psychological distress in a community-dwelling Japanese population: the Ohsaki Cohort 2006 Study. Eur. J. Public Health, 24, 45-49.

Nakaya, N., Nakamura, T., Tsuchiya, N., Narita, A., Tsuji, I., Hozawa, A. \& Tomita, H. (2016a) Prospect of the future housing and the risk of psychological distress at 1 year after 
an earthquake disaster. Psychiatry Clin. Neuros., 70, 182-189.

Nakaya, N., Narita, A., Tsuchiya, N., Nakamura, T., Tsuji, I., Hozawa, A. \& Tomita, H. (2016b) Partners' ongoing treatment for chronic disease and the risk of psychological distress after the Great East Japan Earthquake. Tohoku J. Exp. Med., 239, 307-314.

Nijboer, C., Tempelaar, R., Triemstra, M., van den Bos, G.A. \& Sanderman, R. (2001) The role of social and psychologic resources in caregiving of cancer patients. Cancer, 91, 10291039.

Oba, A., Nakaya, N., Hasumi, M., Ono-Yanaba, K., Saito-Nakaya, K., Takechi, H., Arai, S. \& Shimizu, N. (2014) Psychosocial longitudinal study profile and distress of couples in relation to the conduct of prostate biopsy. Jpn. J. Clin. Oncol., 44, 463-471.

Rhee, Y.S., Yun, Y.H., Park, S., Shin, D.O., Lee, K.M., Yoo, H.J.,
Kim, J.H., Kim, S.O., Lee, R., Lee, Y.O. \& Kim, N.S. (2008) Depression in family caregivers of cancer patients: the feeling of burden as a predictor of depression. J. Clin. Oncol., 26, 5890-5895.

Sjövall, K., Attner, B., Lithman, T., Noreen, D., Gunnars, B., Thome, B. \& Olsson, H. (2009) Influence on the health of the partner affected by tumor disease in the wife or husband based on a population-based register study of cancer in Sweden. $J$. Clin. Oncol., 27, 4781-4786.

Toseland, R.W., Blanchard, C.G. \& McCallion, P. (1995) A problem solving intervention for caregivers of cancer patients. Soc. Sci. Med., 40, 517-528.

Yoshii, K., Kondo, K., Kuze, J. \& Higuchi, K. (2005) Social relationship factors and risk of care requirement in Japanese elderly. Jpn. J. Public Health, 52, 456-467 (in Japanese, Abstract in English). 